\title{
The influence of Three Gorges Reservoir high water level on the rainfall runoff
}

\author{
Biqiong $\mathrm{Wu}^{1}$, Wei Zheng ${ }^{1}$, Xinkai Ren ${ }^{1}$, Tao $\mathrm{Xu}^{1}$ and Xiao Guo ${ }^{1}$ \\ ${ }^{1}$ Three Gorges Cascade Dispatch \& Communication Canter of China Yangtze Power Co., Ltd., 443133 Yichang, China
}

\begin{abstract}
After Three Gorges Reservoir building up, the natural river course and the near hillside inside the backwater region are inundated to form a fairly wide man-made lake which affects the hydrological characteristics and floodwater transmission to different degrees. When the reservoir impound to high water level, the conflux time is obviously shortened, the flood-peak discharge increase, and the peak type became sharper. The change of runoff yield and concentration makes the forecast scheme unable to be applied well. Based on the practice of Three Gorges Reservoir operation, the rainfall-runoff characteristics of the backwater region under the condition of high water level are analysed and summarized, then a set of unit hydrographs suitable for rainfall-runoff calculation are recalibrated, which has great reference value for hydrological forecasting of Three Gorges region.
\end{abstract}

\section{Introduction}

Three Gorges Reservoir is a key project in the Yangtze River basin. Since the reservoir has been successfully impounded in October 2010, it brings into full play the comprehensive benefits, such as flood control and drought relief, power generation, shipping and water supply ${ }^{[1]}$. While, the autumn flood in recent years show that, with the rise of water level, the law of rainfall concentration and channel flood propagation has changed greatly in the backwater area of the reservoir. There are many tributaries in the reservoir area, and the interaction between the trunk and tributaries is extremely complex. After the reservoir impounds, the natural river course and the near hillside inside the backwater region are inundated to form a fairly wide man-made lake, which cause the behaviour of rainfall generation and influx are bound to change ${ }^{[2]}$.

Part of the rainfall in the reservoir area falls directly on the surface of the water, and some of it is quickly collected into the reservoir after generation and influx. Therefore, the forecast earliness of flood in this region is short, and the flood peak is sharp and the flood volume is large, which is a major factor restricting the real-time dispatch of Three Gorges Reservoir. For the situation that the change of hydrological conditions in the reservoir area makes the original prediction scheme unable to be applied well, this paper analyzes and summarizes the characteristics of rainfall runoff in the reservoir area under high water level, and redefines a set of unit lines suitable for high water level, in order to calculate dynamic inflow as a result of heavy rainfall, which has great reference value for improving the accuracy of hydrological forecasting in the backwater region of Three Gorges Reservoir.

\section{Hydrological forecast introduction of Three Gorges region}

\subsection{Introduction of Three Gorges region}

Under the condition of normal storage water level (175m), the length of the river course is more than $600 \mathrm{~km}$, and the backwater can reach Chongqing nearly. Even if the reservoir water level is near the flood limit water level $(145 \mathrm{~m})$, the backwater can reach Qing Xichang, which shows Three Gorges Reservoir is the river-type reservoir $^{[3]}$. The hydrological stations of Three Gorges Reservoir entrance are Cuntan Station and Wulong Station. Therefore, the catchment area between the section of Cuntan and Wulong hydrological stations to the section of Three Gorges Reservoir dam is often called Three Gorges region, also known as Three Gorges interval.

Three Gorges interval is located at the junction of the Sichuan basin and the middle and lower Yangtze River plain $^{[4]}$. The interval has a large amount of rain, with an average annual precipitation of $1130 \mathrm{~mm}$. The study area covers about $56,000 \mathrm{~km}^{2}$, accounting for less than $6 \%$ of upper Yangtze River area, but the average annual runoff account for $8.1 \%{ }^{[5]}$. Because of many tributaries, the East Asian summer monsoon and its complex topography, the Three Gorges region often suffers heavy rain and flood. From 1961 to 2010, the average number of rainstorm days is 3.4, and the average intensity of rainstorm is $72.9 \mathrm{~mm} /$ day $^{[4]}$. Before the construction of the reservoir, the maximum flood peak discharge recorded was 24,600 $\mathrm{m}^{3} / \mathrm{s}$ in July 1982. After the construction of the reservoir,

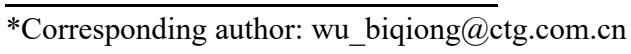


the maximum flood peak flow in the area is about 30,000 $\mathrm{m}^{3} / \mathrm{s}$ in September 2014 .

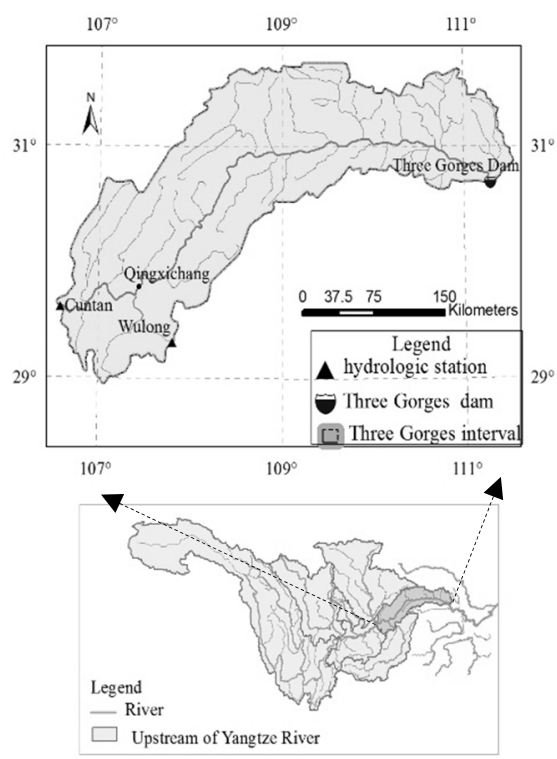

Figure 1. The map of Three Gorges Reservoir area

\subsection{Hydrological forecast introduction of study area}

Because of the influence of the backwater of the reservoir, Three Gorges interval is an uncontrolled area and the discharge cannot be measured directly, which is calculated according to water balance. Since Three Gorges Reservoir is a river-type reservoir, the inflow is divided into static and dynamic reservoir inflow, the calculation difference is whether static or variable capacity variable is based ${ }^{[3]}$. The inflow of static reservoir capacity represents the flow of dam site section, while the inflow of dynamic reservoir capacity represents the flow along the reservoir. Affected by electricity peakadjustment, the process of the static reservoir capacity inflow is serrated, and negative sometimes. Therefore, the inflow prediction scheme based on dynamic reservoir capacity is adopted in this paper.

The hydrological forecasting scheme of Three Gorges interval is regularly revised, but its revision is based on the majority of flood. The principle of selected parameters is the highest qualified rate for several flood calculations. For specific scenes, the accuracy of flood simulation is not so good, such as the high water level of Three Gorges Reservoir. For example, during the autumn flood in 2017, because of continuous heavy rain in Three Gorges interval, the maximum flood peak from Three Gorges interval exceeded $20,000 \mathrm{~m} 3 / \mathrm{s}$. The calculated values of the two forecast schemes, Xin'anjiang ${ }^{[6]}$ and unit line ${ }^{[7]}$, were much lower than the actual values (figure 2). Because of the historical simulation, the model extracted the real temporal and spatial distribution of rainfall, so there is no rainfall forecast error. The two simulation results are very similar, indicating that the same problem exist in two forecast schemes, that is, under high water level, the flood simulation with heavy rainfall is not very suitable.

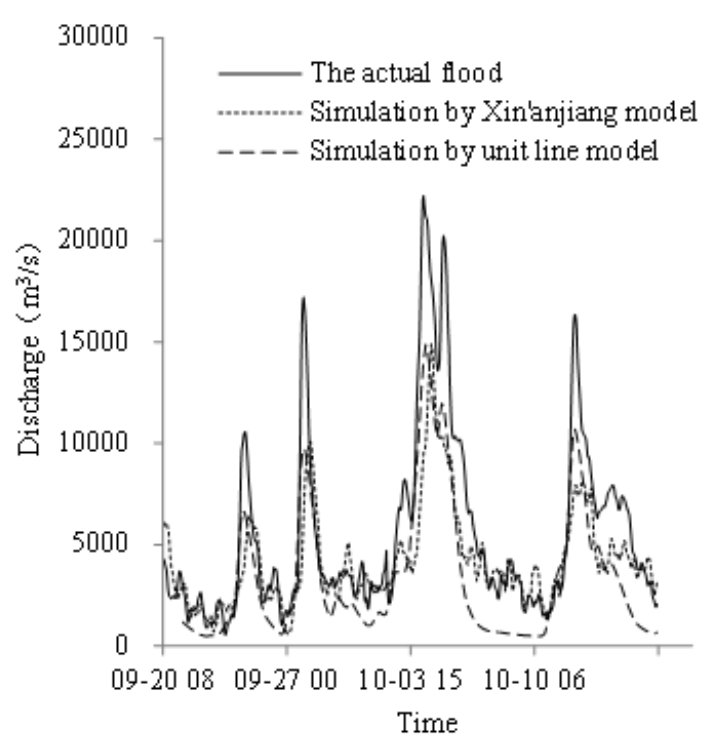

Figure 2. The actual flood compared with simulation by Xin'anjiang and unit line model

\section{Impact analysis of high water level on rainfall-runoff in reservoir area}

\subsection{Qualitative analysis}

The backwater reach of the Three Gorges Reservoir is more than $600 \mathrm{~km}$ long, the reservoir water level changes by $30 \mathrm{~m}$, the distribution of river area, transitional area and reservoir impoundment area also change accordingly. In terms of reservoir water surface area, the water surface area corresponding to the reservoir water level of $145 \mathrm{~m}$ is $521 \mathrm{~km}^{2}$, and corresponding to $175 \mathrm{~m}$ is $1021 \mathrm{~km}^{2}$, with an area difference of $500 \mathrm{~km}^{2}$, equivalent to a small and medium-sized basin where all rainfall translates into runoff.

In natural conditions, runoff formed by rainfall flowed into the estuary along the interval channel. After Three Gorges Reservoir impounded, as the water area expands, more rain will fall directly onto the water surface, and more runoff will flow directly into the reservoir along the periphery of the reservoir. At the same time, as the water surface increases, the evaporation of the reservoir increases accordingly. The regulating function of the natural river channel is greatly reduced or disappeared, which increases the chance that the flood encounter along the periphery of the reservoir. In the matter of flood transmission, with the deepening of water depth and the widening of water surface, the river course which surrounded the beach turned into a downstream channel, and the distance of flood confluence in the reservoir area was shortened. According to the hydrological theory analysis, under high water level, the flood confluence time is shortened so as propagation speed will be significantly accelerated, and the flood peak shall be increased, the peak shape will become thinner.

\subsection{Quantitative analysis}


During the flood season of 2007, the flow from Three Gorges region is restored to natural runoff to compare with the flow after construction of the reservoir (Figure 3 ). The results are consistent with the above theoretical analysis. After impoundment, the peak formation is faster, and the peak time is 6-12 hours earlier than that under natural conditions. What's more, the peak become thinner and sharper, and the peak value increases about $1000 \mathrm{~m}^{3} / \mathrm{s}$. Correspondingly, the water recession time is advanced, and the whole flood process moves forward compared with the original, that is, the discharge of the rising section is higher, while the recession section is opposite. This is because, with the rising of water level, the confluence time is shortened, and the flood propagation speed is obviously accelerated, which is conducive to flood propagation. In addition, the discharge value of the later recession stage is higher than that under natural condition, because this recession is composed of middle soil and underground runoff, when the reservoir water level rises, it is also beneficial to the generation of middle soil and underground runoff.

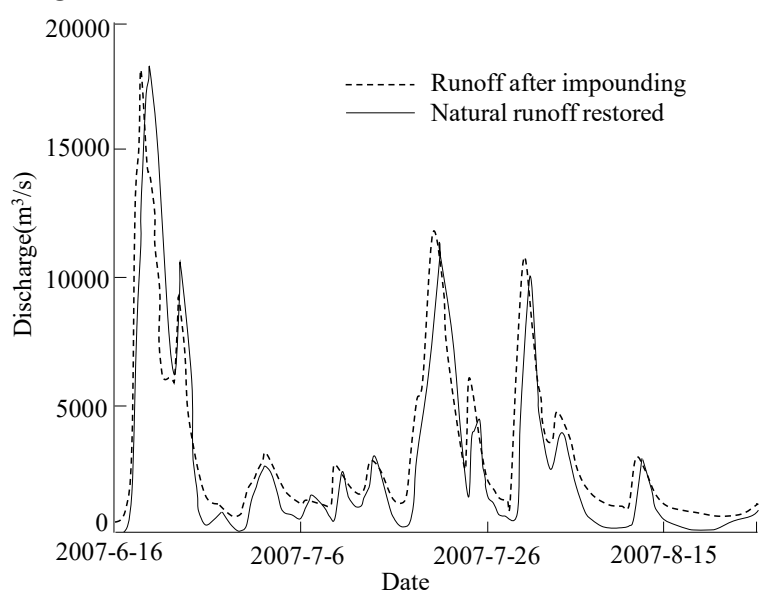

Figure 3. Runoff after impouding and runoff restored under natural condition

When the reservoir water level increases, this rule is more obvious and the effect is intensified. Taking a heavy rainfall that occurred in Three Gorges interval in June 2007 as an example, the runoff process of different water levels were calculated by MIKE model (Figure 4). The influence of reservoir water level on rainfall-runoff are as follows: the reservoir water level is positively correlated with the flood peak flow; flood peak discharge increase by about $9 \%$ maximally. The water flow at rising stage increase, the peak time is slightly advanced and water recession time is also advanced, the flood volume increase slightly. The results show, the reservoir water level is most sensitive to the flood peak.

\section{Calibration of unit line at high water level}

The above analysis shows that the high water level has a significant influence on the rainfall-runoff in Three Gorges interval, the existing forecasting scheme is not very suitable for generation and concentration simulation from heavy rainfall in this region under high water level. Since the unit line method is simple and easy to operate, and has good effect, it is widely used in flood forecasting. Therefore, a few flood from strong rain of Three Gorges area after Three Gorges Reservoir impoundment were selected to determine a set of unit lines.

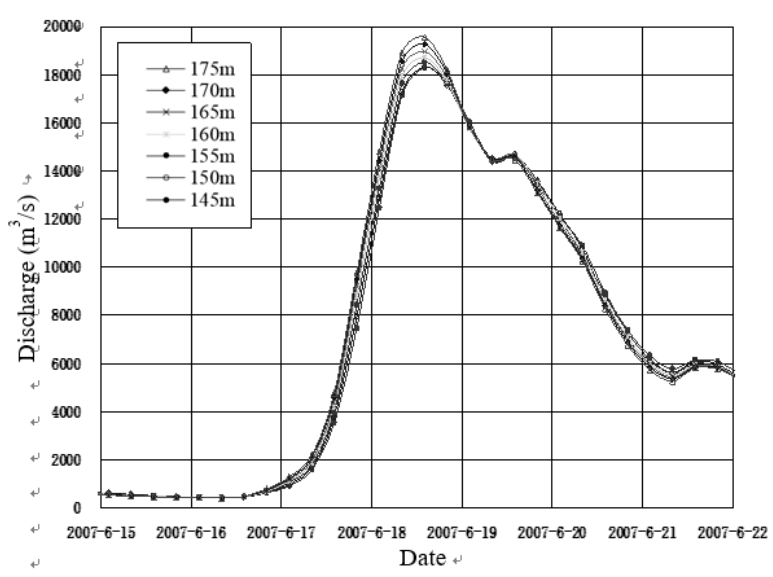

Figure 4. Rainfall confluence at different water levels

\subsection{Data and methods}

Heavy rainfall runoff process in Three Gorges area under high water level $168-175 \mathrm{~m}$ are selected for unit hydrograph calibration. Because the data are selected under specific conditions and because the operation time of the Three Gorges Reservoir is limited, there are few flood that meet the requirements. Finally, five flood are selected to calculate. Because the Three Gorges area is large, and the rain difference between the eastern and western region is obvious ${ }^{[8]}$, so it is divided into two sections for unit hydrograph calibration.

The combination of runoff yield and confluence by unit line can form as a complete hydrological model to simulate rainfall-runoff process. The runoff yield is calculated by using API model (Antecedent Precipitation Index Model $)^{[9]}$. API model is a three-variable correlation diagram of $\mathrm{P}-\mathrm{Pa}-\mathrm{R}$, that is, the effective precipitation $(\mathrm{R})$ can be found through the previous rainfall $(\mathrm{Pa})$ and the current rainfall $(\mathrm{P})$. P-Pa-R correlation varies according to the underlying surface variation in different periods. There are six correlation maps of different periods for Three Gorges area in the whole year, such as dry period, pre-flood period and main flood period. Because the high water level is relatively sensitive to the flood peak, and flood are less to calibrate P-Pa-R trivariate correlation diagram, so the original P-Pa-R correlation diagram is still used to calculate runoff yield. Runoff confluence is computed by Sherman unit line, which is recalibrated by Colin trial-error method ${ }^{[10]}$. This method is most suitable 


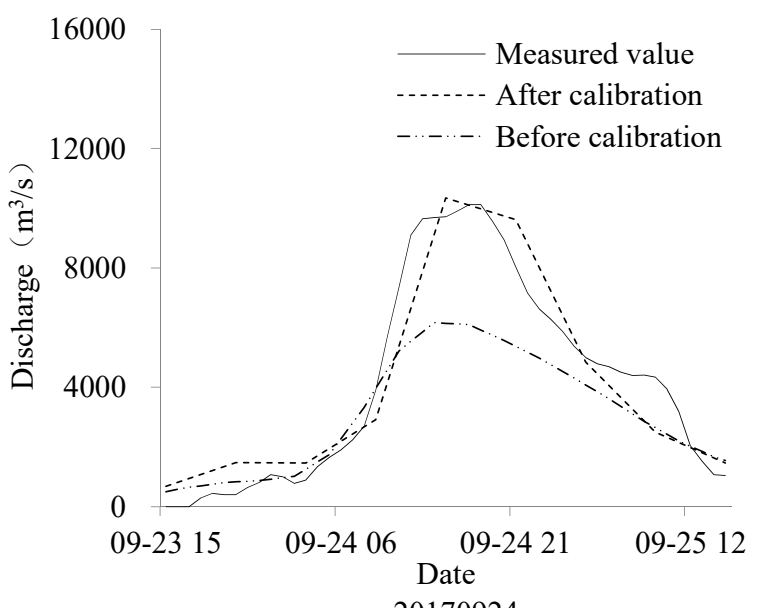

a 20170924

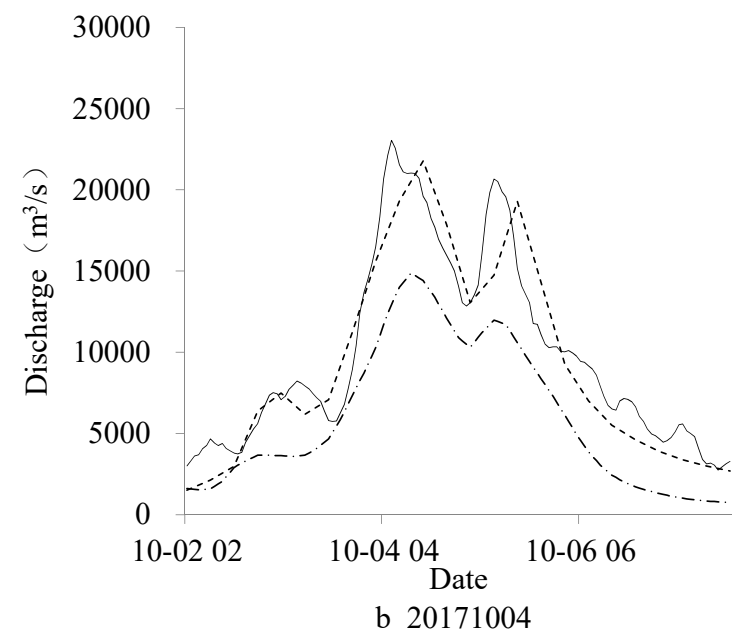

Figure 5. Two flood recalibration results selected

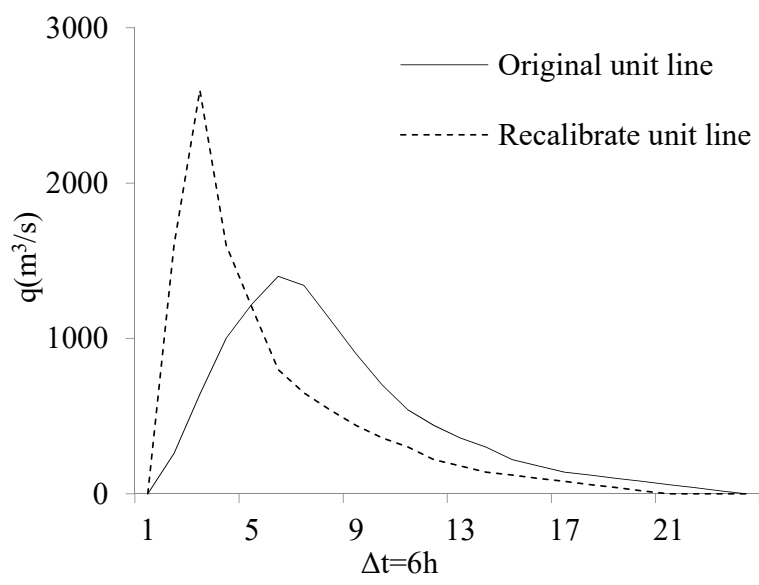

a Western region

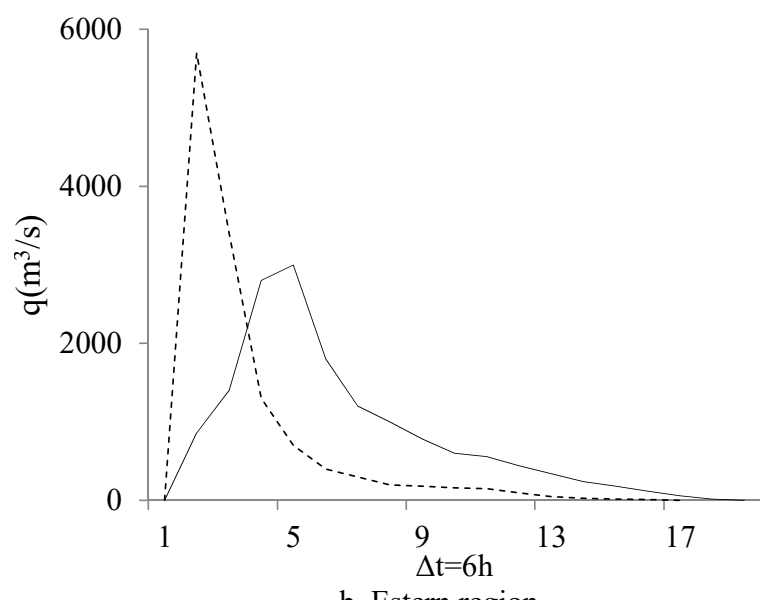

b Estern region

Figure 6. Unit line for western and eastern Three Gorges area comparison between origination and recalibration

for the case of that net rainfall periods are multiple and one period of net rainfall is relatively large. Three Gorges area is a torrential rain area, so the Colin trial-error method is suitable for determining the unit hydrograph.

\subsection{Calibration results}

The steps of unit line calibration are as follows: firstly, the pre-influential rainfall $(\mathrm{Pa})$ is calculated according to the rainfall of 15 days before, then, according to the value of $\mathrm{Pa}$ and rainfall every 6 hours $(\mathrm{P})$, get the net rain depth $(\mathrm{R})$ by API model. Finally, the unit line is calibrated by Colin trial-error method based on the divided flood process. Two flood calibrated results are selected shown in figure

Table 1. The application comparison between the original unit line and the recalibrate unit hydrograph $(\mathrm{m} 3 / \mathrm{s})$

\begin{tabular}{|c|c|c|c|c|c|c|}
\hline \multirow{2}{*}{ Flood } & \multirow{2}{*}{ Element } & \multirow{2}{*}{$\begin{array}{c}\text { Observed } \\
\text { value }\end{array}$} & \multicolumn{2}{|c|}{ Before calibration } & \multicolumn{2}{|c|}{ After calibration } \\
\cline { 4 - 7 } & & Simulation & Error & Simulation & Error \\
\hline \multirow{2}{*}{20170924} & Flood peak & 10300 & 6700 & $-34.95 \%$ & 10100 & $-1.94 \%$ \\
\cline { 4 - 7 } & Peak time & 24 th 18 & 24 th 14 & $-4 \mathrm{~h}$ & 24 th 15 & $-3 \mathrm{~h}$ \\
\hline 20170927 & Flood peak & 17500 & 9700 & $-44.57 \%$ & 16000 & $-8.57 \%$ \\
\hline
\end{tabular}

5. The calculation of flood peak by original unit line is much smaller than the actual value, but the peak time calculation is accurate. After calibration, the calculation accuracy of peak discharge is greatly improved. The relative error is less than $10 \%$, and the calculation of peak time is also better (Table 1). It shows that the unit line is more effective after calibration. Compared with the original unit line (Figure 6), the flood peak becomes sharp and thin, the peak time is advanced, the value of the upstream section is higher than the original unit line, and the value of the recession section is lower, which is consistent with the trend of runoff process from torrential rain under high water level. 


\begin{tabular}{|c|c|c|c|c|c|c|}
\hline & Peak time & 27 th 20 & 27 th 23 & $3 \mathrm{~h}$ & 28 th 02 & $6 \mathrm{~h}$ \\
\hline \multirow{2}{*}{20171004} & Flood peak & 23000 & 14900 & $-35.22 \%$ & 21800 & $-5.22 \%$ \\
\cline { 2 - 7 } & Peak time & 4 th 06 & 4 th 10 & $4 \mathrm{~h}$ & 4 th 14 & $8 \mathrm{~h}$ \\
\hline \multirow{2}{*}{20171012} & Flood peak & 17400 & 8000 & $-54.02 \%$ & 17000 & $-2.30 \%$ \\
\cline { 2 - 7 } & Peak time & 12 th 08 & 12 th 18 & $10 \mathrm{~h}$ & 12 th 10 & $2 \mathrm{~h}$ \\
\hline
\end{tabular}

For testing applicability, the calibrated unit hydrograph of Three Gorges area is applied to the high water level and the general respectively, $175 \mathrm{~m}$ and $160 \mathrm{~m}$ (Figure 7). The results are as follows: the simulation results under high water level are better, the absolute peak error is $1000 \mathrm{~m}^{3} / \mathrm{s}$ and the relative error is only $14.6 \%$, the peak present time is accurate, with a lag time of 0 . The calculation results under general water level are poor, the calculation of flood peak is higher than $6000 \mathrm{~m}^{3} / \mathrm{s}$, with a relative error of $53.4 \%$, while calculation of peak emergence time is accurate, with a lag time of $3 \mathrm{~h}$. The calculation results of two flood show that the revised unit hydrograph is only suitable for the high water level $(168 \mathrm{~m}-175 \mathrm{~m})$, and is not suitable for the runoff calculation under the general water level. In addition, all selected for unit line calibration are torrential rainfall, so the rainfall-runoff response mechanism is fast and the peak shape is thin. If the unit line is applied for small and medium-sized rainfall, the calculation results will be higher than the actual, so this unit line is more suitably applied for heavy rainfall-runoff calculation.

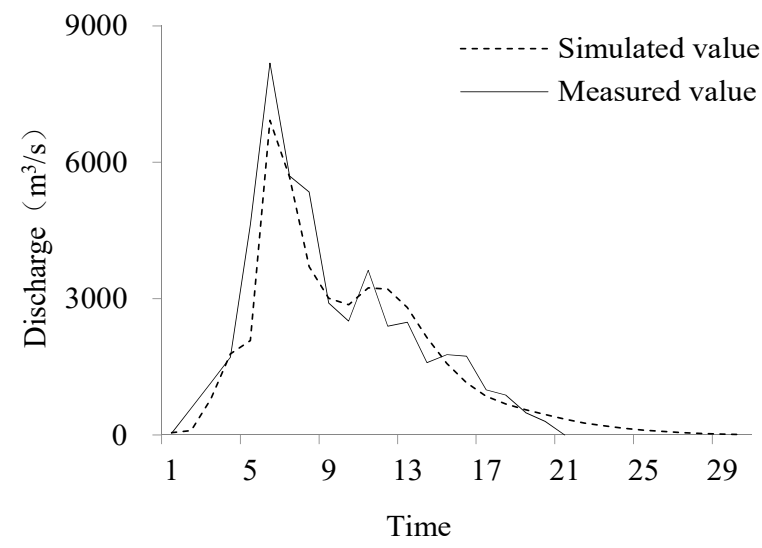

a $175 \mathrm{~m}$

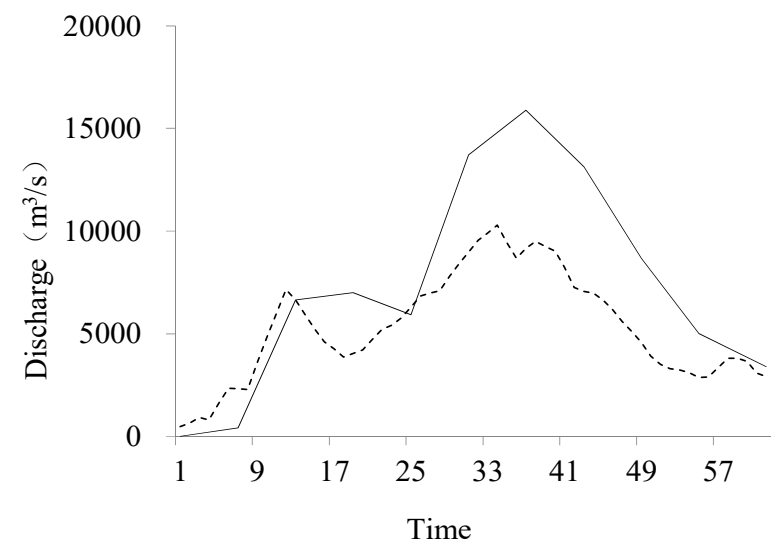

b $160 \mathrm{~m}$

Figure 7. Applied the recalibrated unit line to the high and the general water level (175m and $160 \mathrm{~m})$

\section{Conclusion}

After Three Gorges impoundment, there has been a great change in backwater area of the reservoir and the drainage area, the same as the propagation of river flood. The results of simulating the same flood under different water levels by MIKE model and the reducing reservoir inflow into natural runoff in 2007 flood season show that: after impoundment, when strong rainfall occurs in Three 
Gorges area, the flood peak from Three Gorges area will form faster and peak flow will increase, the time of water recession will advance, and the total inflow will increase slightly. When the reservoir water level increases, this phenomenon becomes more obvious and the effect intensifies. In this paper, the flood under high water level are used to re-calculate the unit line of Three Gorges area, so as to improve the accuracy of hydrological forecast and facilitate the optimal operation of Three Gorges Reservoir. The unit line characteristics after determination are consistent with the actual flood characteristics, and it has good applicability for the calculation of runoff under heavy rainfall and high water level. The data used in this calibration are limited, with the increase of the data from Three Gorges Reservoir, the hydrological forecasting schemes for different water level will be improved in the later stage, including empirical and practical hydrological models and complex physical hydrological models.

\section{ACKNOWLEDGMENT}

Foundation: National "12th Five-Year" water special project (2014ZX07104-005)

\section{References}

1. Z. F. Bao, X. Wang, W. M. Shu, Hydro. A. N. E., 12, 7 (2015)

2. W. M. Zhang, Q. P. Li, Z. F. Bao, Y. Q. Zhang, W.P., 43, 10 (2017)

3. J. J. Zhou, G. W. Chen, J. Yuan, J. of Hydro. Een., 32, 165 (2013)

4. Q. Guo, W. H. Luo, B. Y. Chen, W. G. Sun, Res. Sci., 33, 1513 (2011)

5. X. W. Ji, Hydrology Research of Three Gorges Project (Hubei P. of S. T.1997)

6. L.P. Zhao, W. M. Bao, K. Zhang, J. of Jilin U.(E. S. E.), 44, 3012014$)$

7. B. X. Tong, Z. J. Li, Y. H. Wen, W. P., 43,19(2017)

8. Q. Gao, M. Xu, B. Li, Advances in Met S\&T , 8, 74 (2018)

9. L. Cao, J. C. Chen, EWRHI., 38, 31 (2017)

10. W. M. Bao, Hydrologic Forecast (Water Pub., 2008) 